\title{
Reflexões em um espaço virtual de formação de professores de matemática ${ }^{1}$
}

\author{
Sueli Liberatti Javaroni \\ Maria Teresa Zampieri
}

\begin{abstract}
Resumo: Neste artigo discorre-se sobre um recorte de dados provenientes de um curso de extensão universitária realizado com professores de Matemática. Esse curso foi uma das ações do projeto "Mapeamento do uso das tecnologias da informação nas aulas de Matemática no Estado de São Paulo"4. Traz-se aqui parte das discussões do fórum do ambiente virtual Moodle, sobre uma atividade com o software GeoGebra, em que se abordou o Teorema de Pitágoras. Analisaram-se as discussões com base na ideia de Multiálogo e evidenciaram-se conversas entrecruzadas, que culminaram em propostas e adaptações na atividade inicial, feitas pelos professores, buscando contemplar seus respectivos ambientes educacionais.
\end{abstract}

Palavras-chave: GeoGebra, rizoma, OBEDUC, Educação Matemática

\section{Reflections in a virtual space of math teacher training}

\begin{abstract}
This article discusses about a data from a course of university extension held with Mathematics teachers. This course was one of the activities of the project "Mapping the use of information technology in Mathematics classes in São Paulo". Brings up here part of the discussions that took place in the forum of the virtual environment Moodle, about an activity with GeoGebra software in which we approached the Pythagorean theorem content. Were analyzed discussions grounded on the idea of Multiálogo and become evident crisscrossed talks, culminating in proposals and adaptations in this activity, made by teachers, seeking to contemplate their educational environments.
\end{abstract}

Keywords: GeoGebra, rhizome, OBEDUC, Math Education

\section{Introdução}

Neste artigo temos o propósito de apresentar e discutir um recorte dos dados provenientes de um curso de formação continuada para professores de Matemática,

1 O presente trabalho foi realizado com o apoio da Coordenação de Aperfeiçoamento de Pessoal de Nível Superior (Capes), entidade do Governo brasileiro voltada para a formação de recursos humanos.

2 Doutora em Educação Matemática pela UNESP-Rio Claro em 2007. Professora da Faculdade de Ciências da UNESP - Bauru e do Programa de Pós-Graduação em Educação Matemática da UNESP - Rio Claro. E-mail: suelilj@fc.unesp.br.

3 Doutoranda em Educação Matemática pela UNESP - Rio Claro (Bolsista FAPESP, processo \#2014.271669).E-mail: maite.zampieri@gmail.com.

4 Projeto de pesquisa aprovado sob número 16429, Edital 049/2012/CAPES/INEP/OBEDUC - Observatório da Educação. Retirado em 19 de janeiro de 2016, de http://www.capes.gov.br/educacao-basica/ observatorio-da-educacao 
que ocorreu na Diretoria de Ensino de Bauru e fez parte das ações que vêm sendo realizadas dentro do projeto "Mapeamento do uso das tecnologias da informação nas aulas de Matemática no Estado de São Paulo”, vinculado ao Programa Observatório da Educação (OBEDUC), aprovado no Edital 049/2012/CAPES/INEP. Este recorte foi extraído de atividades propostas na plataforma Moodle, Ambiente Virtual de Aprendizagem (AVA) do curso, com um total de 40 horas de carga horária: 32 horas presenciais e 8 horas virtuais.

Esse curso, que teve como cenário a Diretoria de Ensino de Bauru, atendeu a um objetivo específico do referido projeto: propiciar ações de formação continuada para professores de Matemática ligados às Diretorias de Ensino de Bauru, Guaratinguetá, Limeira, Presidente Prudente, Registro e São José do Rio Preto, cidades do estado de São Paulo. Entretanto, esse objetivo específico está diretamente atrelado ao objetivo central do projeto, que busca identificar como as tecnologias digitais vêm sendo utilizadas nas aulas de Matemática dos anos finais do Ensino Fundamental II da Educação Básica no estado de São Paulo.

Os resultados de algumas pesquisas vinculadas às Diretorias de Ensino de Bauru (Andrade \& Baldoni, 2014; Andrade, Baldoni, \& Javaroni, 2014; Oliveira, 2014), Limeira (Borges, 2014; Chinellato, 2014; Chinellato \& Javaroni, 2013; Chinellato \& Javaroni, 2014; Silva, Zampieri, Javaroni, \& Chinellato, 2014), Guaratinguetá (Firme \& Paulo, 2014), São José do Rio Preto (Freitas, 2014) e Presidente Prudente (Medeiros, 2014) apontam que muitos percalços inviabilizam a integração dos computadores nas aulas de Matemática, como: número insuficiente de computadores para o número de estudantes por sala, ausência de técnicos responsáveis pelos laboratórios, ausência de estagiários vinculados ao programa Acessa Escola ${ }^{5}$ nos três turnos de funcionamento das escolas. Tal programa tem o propósito de promover a inclusão digital e social de alunos, funcionários e professores que atuam na rede estadual pública paulista.

Além disso, encontramos indícios de possíveis dificuldades envolvendo a formação de professores, o que vai ao encontro do que Bonilla e Oliveira (2011) relatam sobre cursos de formação continuada. Eles alegam que poucos cursos articulam conteúdo programático com as tecnologias e ainda desconsideram "os processos de imersão e familiarização desses professores nos ambientes e na cultura digitais” (p.39-40).

Diante disso, quando surgiu a oportunidade de aplicarmos um curso de formação continuada, em formato de curso de extensão universitária, para professores de Matemática da Diretoria de Ensino - Regional de Bauru, estado de São Paulo, fizemos um amplo estudo com os colaboradores do projeto, com o intuito de atender às necessidades dos professores, de forma a provocar reflexões sobre a integração

5 Retirado em 20 de janeiro de 2016, de http://acessaescola.fde.sp.gov.br/Public/Conteudo.aspx?idmenu=11 
das tecnologias digitais dentro do contexto da sala de aula de Matemática. Tais colaboradores são professores do ensino básico, atuantes em sala de aula, ou professores coordenadores do núcleo pedagógico das diretorias de ensino envolvidas, além dos pesquisadores colaboradores, docentes e estudantes de Licenciatura em Matemática da Universidade Estadual Paulista (Unesp), bem como os discentes de mestrado e doutorado do Programa de Pós-Graduação em Educação Matemática do Instituto de Geociências e Ciências Exatas (IGCE) da Unesp, campus de Rio Claro, estado de São Paulo.

\section{O desenvolvimento do curso}

Conforme já mencionamos, o curso contou com uma carga horária de 40 horas, 32 presenciais e 8 a distância, com discussões no fórum do AVA sincronamente. Ministrado pela doutoranda envolvida no projeto, segunda autora deste artigo, contou com a monitoria, presente em todos os encontros, de duas alunas de graduação que desenvolvem pesquisas de iniciação científica, também vinculadas ao projeto; e com a colaboração da pesquisadora coordenadora do projeto, primeira autora deste artigo, e da professora coordenadora de Matemática do núcleo pedagógico da Diretoria de Ensino de Bauru. Estes foram os objetivos principais: incentivar a integração das tecnologias digitais, em particular o GeoGebra, nas práticas dos professores de Matemática da Educação Básica e promover discussões sobre assuntos que permeiam essa integração. No decorrer dos encontros presenciais, sugerimos que os professores trabalhassem em duplas ou trios.

O curso foi organizado em módulos. No módulo 1, tínhamos a finalidade de “ouvir" os professores acerca de suas expectativas e também verificar a experiência de cada um quanto ao uso de tecnologias digitais no contexto educacional. Nesse momento, ficou claro para nós que eles estavam com o foco totalmente voltado para a exploração do GeoGebra e tinham o interesse em aprofundar o conhecimento nesse software. Além disso, pudemos perceber os contratempos enfrentados por eles para levar os alunos aos laboratórios de informática de suas respectivas escolas, pelos mesmos motivos já elencados anteriormente, observados em outras pesquisas vinculadas ao projeto.

Nessa ocasião, enfatizamos que o curso estava sendo criado em parceria com eles, para que suas expectativas fossem atendidas, já que "a educação autêntica, [...] não se faz de A para B ou de A sobre B, mas de A com B, mediatizados pelo mundo" [ênfase no original] (Freire, 2005, p. 97). Desse modo, os professores elencaram os conteúdos matemáticos de seu interesse, para que as atividades contemplassem a ementa sugerida. Após essa discussão, foram convidados a se sentar em duplas ou trios, junto aos computadores, e passamos a apresentar os recursos do software 
BlueLab $^{6}$, disponível em todas as escolas cadastradas no Acessa Escola, com a função de auxiliar o professor a organizar a sua aula dentro do Laboratório de Informática, por meio de recursos como compartilhamento de telas, compartilhamento de arquivos, envio de questionários, etc. Em seguida exploramos também alguns recursos matemáticos dos componentes da Microsoft Office (editor de texto e planilha). Ao longo das atividades, observamos que, de um modo geral, a maioria dos professores tinha habilidade para manusear os recursos trabalhados nesse primeiro dia, e mesmo os que não tinham se movimentaram e exploraram os recursos. Notamos também que professores que terminaram mais rápido ajudaram outros com mais dificuldades. Ressaltamos ainda que esse módulo foi inicialmente pensado para ocorrer em dois encontros. Contudo, nós o realizamos em um encontro, pois priorizamos atender as expectativas dos professores para começarmos de imediato a exploração do GeoGebra.

No módulo 2, tivemos o intuito de iniciar a exploração das ferramentas básicas do GeoGebra com uma breve explicação, exposta no projetor multimídia. Em seguida, a exploração foi conduzida por meio de propositura de atividades matemáticas baseadas nos conteúdos elencados pelos professores, fazendo uso dos recursos mais básicos do software. Contudo, notamos que a maioria dos professores participantes realizava rapidamente tais atividades, com o foco no aprofundamento do software de uma maneira geral, sem necessariamente pensar em suas respectivas salas de aula. Após a realização de cada atividade, fazíamos uma discussão coletiva para que os professores tecessem críticas às atividades e/ou apontassem sugestões de outras abordagens.

A comunicação que estabelecemos com eles por meio dessas discussões contribuiu para uma mudança de foco. Ou seja, depois de certo tempo, eles já não estavam mais pensando somente em aprofundar os conhecimentos acerca do software, mas buscavam, principalmente, articulá-los aos conteúdos abordados no curso, para potencializar a aprendizagem de seus respetivos alunos. Um exemplo dessa mudança de foco foi evidenciado no terceiro encontro, após uma atividade sobre área e perímetro de figuras planas: em uma tabela em que os valores dos lados das figuras deveriam ser inseridos manualmente, os professores sugeriram que fosse feita uma adaptação na abordagem que propusemos, para que os dados fossem inseridos automaticamente, pois assim eles poderiam explorar e aprender um número maior de funcionalidades do software.

Contudo, em meio a essa comunicação, começamos a pensar em distintos contextos de sala de aula em que a atividade pudesse ser desenvolvida, e os professores

6 Retirado em 23 de janeiro de 2015, de http://www.blueonline.com.br/ 
concluíram que, dependendo da abordagem em que estivessem trabalhando, a automatização da tabela nem sempre seria pertinente para a construção dos conceitos de área e perímetro. Concomitantemente ao desenvolvimento das atividades com o GeoGebra, os professores exploravam os recursos do BlueLab em duplas ou trios, com a ajuda das alunas de graduação. Eles se entusiasmaram com a ferramenta "Questionário" do BlueLab, argumentando que ela poderia facilitar a criação de avaliações e/ou atividades, e apontaram a ferramenta "enviar arquivo" do BlueLab dos alunos, como limitada, já que não possibilita o envio de vários arquivos de uma vez para o professor. Vale ressaltar ainda que todas as sugestões dos professores para melhoria desse software estão sendo informadas à empresa responsável por seu desenvolvimento.

O módulo 3 ocorreu simultaneamente ao segundo módulo. Em um primeiro momento, a ideia para esse último módulo seria de que os professores elaborassem atividades tendo em mente o contexto em que elas poderiam ser aplicadas, ou seja, pensando nos laboratórios de informática dentro de seus respectivos locais de trabalho, os quais funcionam de acordo com as normas do programa Acessa Escola. Contudo, logo após isso ter sido sugerido no terceiro encontro, alguns professores foram além desse plano: adaptaram algumas atividades realizadas no curso -, por exemplo, com o Teorema de Pitágoras e o Teorema de Tales -, aplicaram-nas no trabalho com seus alunos e as apresentaram nos encontros do curso.

Essas apresentações fomentaram a comunicação entre os professores, e, dentre as temáticas levantadas, destacamos: GeoGebra despertou a atenção de alunos que normalmente não se manifestam nas aulas; há necessidade de mais atenção no planejamento de aulas com softwares; a burocracia do Acessa Escola em relação à manutenção dos computadores e ao (des) preparo de alguns estagiários vinculados ao programa atrapalha o uso dos laboratórios; o apoio da escola faz toda a diferença para o uso dos laboratórios; foram feitas adaptações das atividades articuladas às situações de aprendizagem do material didático do estado de São Paulo e a questões do Sistema de Avaliação de Rendimento Escolar (SARESP), etc.

Além dos encontros presenciais, conforme já anunciado, o curso também propiciou momentos virtuais no AVA Moodle. A dinâmica adotada nos dois encontros virtuais no Moodle foi decidida em comum acordo com os professores. Foi programado que as atividades propostas seriam disponibilizadas no início da semana, e no sábado, das $9 \mathrm{~h}$ às $11 \mathrm{~h}$, haveria um encontro síncrono no AVA, com o intuito de realizar uma análise crítica da atividade, visando ao seu aprimoramento, baseado nas vivências de sala de aula. No decorrer da semana, caso os professores participantes quisessem, poderiam desenvolver as atividades em suas salas de aula e comentá-las assincronamente no fórum. 
Observamos que, virtualmente, a comunicação foi expandida, pois presencialmente, os professores acabavam se comunicando mais intensamente com os colegas que se sentavam próximos a eles. Já no AVA, a comunicação perpassou os grupos, ou seja, muitos professores de distintos grupos, que não se comunicavam com frequência presencialmente, estreitaram o diálogo no ambiente virtual, e alguns que não tinham hábito de se manifestar nos debates dos encontros presenciais expuseram suas opiniões e participaram ativamente das discussões no fórum. Ressaltamos ainda que nos comunicamos de maneira assíncrona, ao longo de todo curso, em um grupo fechado na rede social Facebook e também por e-mail, com o intuito de trocar informações referentes a cada encontro. Os frutos dessa comunicação, presencial e virtualmente, resultaram em sugestões de adaptações nas atividades, visando à produção de conhecimento matemático de seus respectivos alunos.

Após essa breve apresentação do curso de formação continuada, fruto do projeto Mapeamento do uso das tecnologias da informação nas aulas de Matemática no estado de São Paulo, ligado ao OBEDUC, passamos a analisar aspectos emergentes desse ambiente que se formou com pesquisadores e professores do ensino básico.

\section{O multiálogo e as características observadas no ava}

Borba (2004) define

por multiálogos o acontecimento de diversos diálogos entrecruzados, como os ocorridos em salas de bate-papo, com os membros envolvidos em várias discussões, e um dado aluno "saltando" de um para o outro, ou participando de mais de um diálogo. É esta natureza da sala de bate-papo que modifica a natureza da produção do conhecimento. (p. 304)

Embora o autor esteja com o foco voltado para a sala de bate-papo, consideramos que essas características do multiálogo, em particular os diálogos cruzados, podem ser evidenciadas em outros ambientes online, como discussões que acontecem em fóruns dentro do Moodle ou outro AVA, e até mesmo naqueles cuja finalidade nem é a pedagógica, como a rede social Facebook. Além disso, dentro desse contexto em que estamos inseridas, não foram os alunos os protagonistas do multiálogo, mas, sim, os professores. Logo, não evidenciamos mudanças na natureza da produção do conhecimento matemático de nossos protagonistas, mas, sim, na produção de conhecimento acerca das funcionalidades do GeoGebra, a qual pode ser observada no modo como articularam os conteúdos matemáticos com abordagens distintas das que propusemos, na medida em que exploraram o software pensando na produção de conhecimento matemático de seus alunos. 
Já, no que tange às características fundamentais que deveriam ser contempladas em ambientes virtuais de aprendizagem, de maneira geral, corroboramos a afirmação de Ferreira, Zampieri e Queiroz (2013), quando argumentam que um AVA “deve permitir que o participante contribua de alguma forma [para a comunicação], seja publicando mensagens, modificando documentos, dentre outras possibilidades, favorecendo a exploração e a conversação entre os participantes, ou seja, que eles se integrem" (pp. 3-4).

As pesquisadoras, apoiadas em Deleuze e Guattari (1995), defendem que um AVA, ou um ambiente online adaptado para ser um AVA, quando funciona desse modo, pode apresentar algumas características de rizoma. Por sua vez, esses autores explicam o rizoma como sendo um sistema cuja expansão não se dá de maneira ramificada ou arborescente. Por meio de uma metáfora envolvendo teatro de marionetes, eles argumentam que essa expansão se dá de modo análogo ao movimento dos fios dentro de tal espetáculo, pois eles "não remetem à vontade suposta una de um artista ou de um operador, mas à multiplicidade das fibras nervosas que formam por sua vez uma outra marionete seguindo outras dimensões conectadas às primeiras" (Deleuze \& Guattari, 1995, p. 15). Eles também relacionam a ideia de rizoma com a forma de escrita de Kleist ${ }^{7}$, pelo fato de ele ter rompido com textos constituídos pelo foco em um sujeito ou em uma substância. Para os autores, Kleist conseguia reunir multiplicidades de ideias em uma só página, como, por exemplo: determinações históricas, formações sociais, indivíduos, grupos, acontecimentos vividos, etc.

Diante dessas ideias, argumentamos que, independentemente do ambiente virtual em que se esteja interagindo, quando ele é utilizado para fins pedagógicos, o multiálogo pode se fazer presente. E essa natureza de discussões entrecruzadas que muda a produção de conhecimento também possibilita que esse ambiente apresente características rizomáticas, não se expandindo de maneira ramificada. Não estamos afirmando que o AVA funcione exatamente como um rizoma, mesmo porque esse conceito defendido por Deleuze e Guattari (1995) é amplo, e os autores o definem, em particular, para fugir de pensamentos dicotômicos e de qualquer tipo de representação de situações reais. Assim, apenas mencionamos que os AVA podem apresentar algumas características rizomáticas quando a comunicação se expande de modo análogo ao teatro de marionetes, conforme já mencionamos aqui, e possibilitam que a comunicação tome rumos inesperados, sendo conduzida não pela vontade do responsável por aquele curso ou aula que está acontecendo no ambiente, mas, sim, pelas fibras nervosas daqueles que se manifestam (digitando, anexando imagens, etc.) e interagem.

7 Sobre a biografia do poeta Kleist, consultar http://www.goethe.de/ins/br/lp/kul/dub/tut/pt7849514. htm Retirado em o6 de março de 2016. 


\section{A comunicação no fórum de discussões}

Em um dos dois encontros online, propusemos aos professores duas atividades: uma sobre Teorema de Pitágoras e a outra sobre Relações Métricas no Triângulo Retângulo, conteúdos esses elencados anteriormente por eles. O objetivo da primeira era que os alunos ${ }^{8}$ observassem as relações entre as áreas dos quadrados dos catetos com a área do quadrado da hipotenusa. Para isso, o ângulo de 90 o do triângulo permaneceria estático, mas seu tamanho e sua posição poderiam ser alterados de qualquer modo, apenas movimentando os pontos A, B e C. A construção final pode ser observada na Figura 1, apresentada a seguir.

Figura 1 - Atividade pronta do Teorema de Pitágoras.

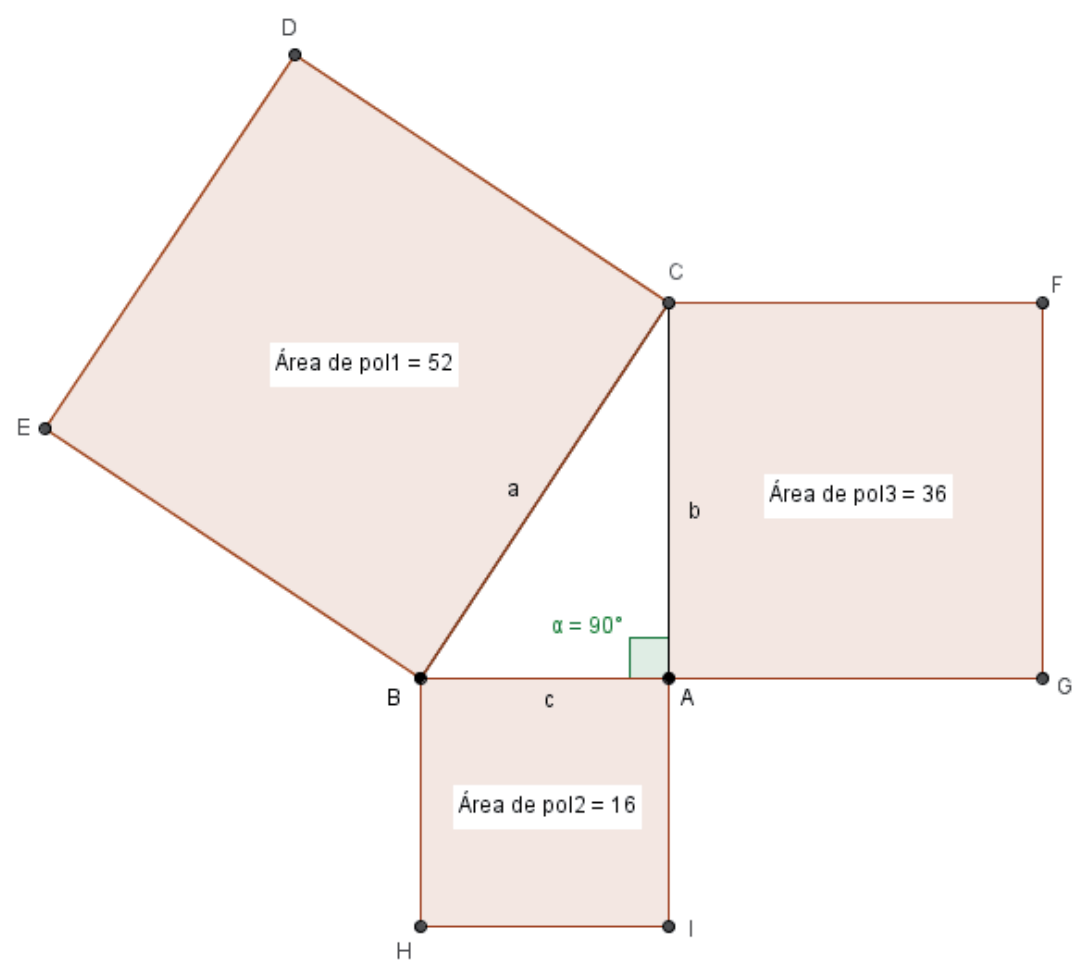

Fonte: Dados da pesquisa de doutorado da segunda autora.

O roteiro para a construção foi anexado ao fórum no início da semana, e as discussões síncronas aconteceram no sábado posterior. Visando fomentar as discussões, colocamos a seguinte mensagem:

Olá pessoal, tudo bem? Conforme combinado, estou postando as atividades de nosso I Encontro Virtual, para que vocês possam realizá-las de acordo com seus melhores horários ao longo dessa semana, e para que possamos discutir no sábado,

8 Quando usamos o termo "alunos", nos referimos aos alunos dos professores cursistas, pois as atividades eram desenvolvidas com o intuito de que os professores posteriormente pudessem fazer adaptações nelas para desenvolvê-las em seus contextos de trabalho. 
das 09:00 às 11:00. Estamos à disposição também para tirar dúvidas e/ou debater ao longo da semana!

A partir disso, muitos comentários foram surgindo ao longo da semana, alguns com o propósito de sanar dúvidas, outros com o propósito de apenas anexar as atividades resolvidas, dentre outros. No sábado iniciamos as discussões síncronas no fórum e observamos muitas adaptações nas atividades, as quais foram compartilhadas pelos professores.

A primeira participante a sugerir adaptações foi a professora Carina ${ }^{9}$, que propôs que fosse exibida uma planilha junto com a construção, para que as áreas e suas variações também pudessem ser observadas, além das que já constavam na figura. Além disso, ela acrescenta:

Pensando em "desafiar" nossos alunos poderíamos pedir para realizarem o mesmo procedimento, porém construindo um triângulo através do polígono regular, e assim realizarem suas observações e conclusões. Creio que com eles observando a diferença consigam entender e guardar melhor as propriedades do teorema. (Professora Carina, fórum de discussões)

Nesse momento, nós não havíamos entendido ao certo a ideia da professora sobre fazer outra construção desconsiderando o ângulo reto, por isso a questionamos sobre esse procedimento em outra mensagem no fórum. Ao mesmo tempo, respondemos a Camila, outra professora cursista, sobre as adaptações que ela já havia sugerido anteriormente. Camila também havia tido a ideia de construir uma planilha ao lado da figura, para que as variações das áreas pudessem ser visualizadas quando a figura fosse movimentada. Ela argumenta:

Só acrescentaria no roteiro a construção da soma das áreas dos quadrados menores em uma planilha, simples mesmo, para que eles possam somar os valores e comparar com o quadrado maior e a cada vez que mexer no triangulo ir fazendo esse processo comparando. (Professora Camila, fórum de discussões)

Contudo, observamos que a planilha feita pela professora mantinha os valores estáticos, isto é, ao movimentarmos o triângulo da construção, as medidas da planilha não variavam, visto que os dados da planilha não estavam relacionados por nenhum comando do software aos dados que constavam na figura. Sendo assim, avisamos a ela acerca dessa limitação e nos debruçamos na construção, para poder colaborar com as adaptações propostas pela professora.

9 Alteramos os nomes dos professores para preservar sua privacidade. 
Logo em seguida, a professora Carina esclareceu suas ideias sobre a construção de um outro triângulo não retângulo:

Eu pensei na construção no triângulo como polígono regular, para eles observarem que não podemos aplicar o teorema em qualquer triângulo e chegarem a conclusão que é necessário o ângulo de 90o (triângulo retângulo). Para nós isso é muito óbvio, mas para eles não. Se demonstramos, pedindo para que eles observem esse detalhe, a construção do conceito será mais significativa, creio eu. (Professora Carina, fórum de discussões)

A construção de Carina, envolvendo as duas figuras planas e a planilha, pode ser visualizada na Figura 2, a seguir.

Figura 2 - Tela do GeoGebra com a construção elaborada por Carina.
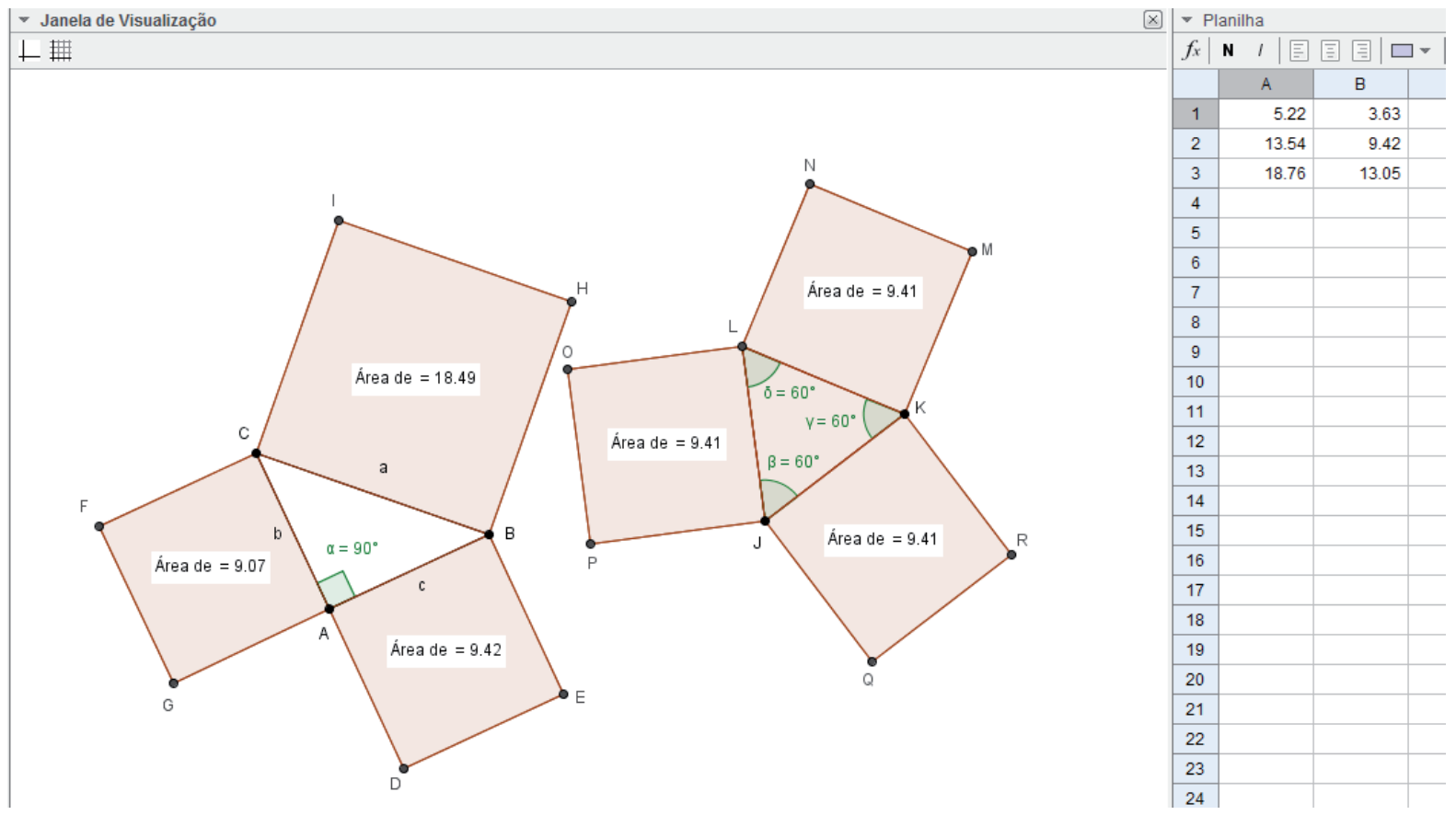

Fonte: Dados da pesquisa de doutorado da segunda autora.

Como estávamos conversando ao mesmo tempo com outros professores no fórum, acabamos não refletindo acerca dessa resposta de Carina. Analisando posteriormente, observamos que ela teve uma ideia interessante para que os alunos pudessem comparar o que acontece no triângulo retângulo com o que acontece em triângulos quaisquer, para que eles entendessem que o teorema só se aplica no primeiro caso. No entanto, ela mencionou a construção desse triângulo qualquer utilizando a funcionalidade polígono regular do GeoGebra, mas isso deveria ser feito apenas utilizando a funcionalidade polígono, pois, para fazer essa comparação, bastaria criar um triângulo qualquer sem ângulo reto, e não necessariamente equilátero. 
Outro ponto que merece destaque nessa resposta é o trecho "se demonstramos, pedindo para que eles observem esse detalhe, a construção do conceito será mais significativa, creio eu”. A professora sugeriu, como já mencionado, que a construção dos quadrados de lados iguais aos catetos fosse também feita para outros triângulos, além do triângulo retângulo. No entanto, analisando a abordagem adaptada que ela compartilhou (Figura 2), observamos que o que acontece é uma verificação da validade do Teorema e das condições necessárias para que ele seja aplicado, e não se trata de uma demonstração, que solicita um rigor matemático, utilizando-se de métodos dedutivos, indutivos ou de reducionismo ao absurdo. Mas podemos dizer que se trata de uma experimentação, propiciada pelo dinamismo do software, ao possibilitar a simulação do cálculo das áreas envolvidas, que, dependendo dos objetivos que o professor queira atingir com seus alunos, pode culminar em possibilidades para a demonstração.

De todo modo, concordamos com a professora Carina, quando ela argumentou que essa abordagem comparativa seria mais significativa no entendimento desse conceito pelos alunos. E ainda acrescentamos que a dinamicidade do GeoGebra, que, por sua vez, possibilita articular álgebra e geometria, permite que mais abordagens comparativas como essa sejam realizadas para trabalhar outros conceitos que envolvem aplicação de teoremas e propriedades, bem como para visualizar as condições necessárias para utilizá-los, cabendo aos professores a decisão de avançar ou não para as demonstrações mais rigorosas, a partir dessas abordagens exploratórias.

Chegamos a trabalhar com tais aplicações ao longo do curso, como nessa atividade e em outra sobre o teorema de Tales, mas não nos atentamos para chamar a atenção dos professores para avaliarem o potencial do GeoGebra para essas abordagens comparativas ou até mesmo para a possibilidade de realizar demonstrações. Mas seria um tema pertinente para trabalharmos em edições futuras do curso ou em outras ocasiões. Argumentamos ainda que o Multiálogo (Borba, 2004), com suas conversas entrecruzadas, seja na sala de bate-papo, seja em fóruns de discussões ou até mesmo em outros ambientes virtuais, pode contribuir para que muitas abordagens como essa sugerida por Carina sejam discutidas e avaliadas por professores atuantes nesse nível de escolaridade, tendo em mente o entendimento de outras propriedades e teoremas em sala de aula.

Voltando à discussão no fórum, ao mesmo tempo em que visualizamos essa resposta de Carina acerca de nosso questionamento sobre sua adaptação, estávamos pensando ainda sobre como automatizar a planilha da atividade de Camila e sugerimos a ela alguns comandos para fazer isso. Logo em seguida, Carina colocou um comentário, afirmando ter gostado da sugestão de deixar a planilha automatizada, pois nessa adaptação que ela fez (Figura 2) os dados deveriam ser inseridos manualmente. 
Em seguida, Camila se manifestou: "isso mesmo, deu certo...somei depois A7 e B7...Quer que envie novamente a atividade? Carina, gostei muito da ideia!”. Nessa última frase, Camila estava se referindo à ideia de Carina para acrescentar outra construção ao original, envolvendo um triângulo não retângulo.

Paralelamente a essas discussões, a professora cursista Laura sugeriu que essa atividade poderia ainda ser adaptada para atender a uma situação de aprendizagem do Material didático oficial do estado de São Paulo (São Paulo, 2014). Essa situação de aprendizagem tem o propósito de propiciar que o aluno entenda a relação entre as medidas do comprimento da circunferência e o diâmetro. A adaptação sugerida pela professora, além de cumprir o objetivo dessa situação de aprendizagem e o objetivo da atividade que propusemos, possibilita a visualização de que a soma das áreas dos semicírculos com o diâmetro coincidindo com os catetos menores é igual à área do semicírculo com o diâmetro coincidindo com a hipotenusa. Sua abordagem pode ser visualizada na Figura 3, apresentada a seguir.

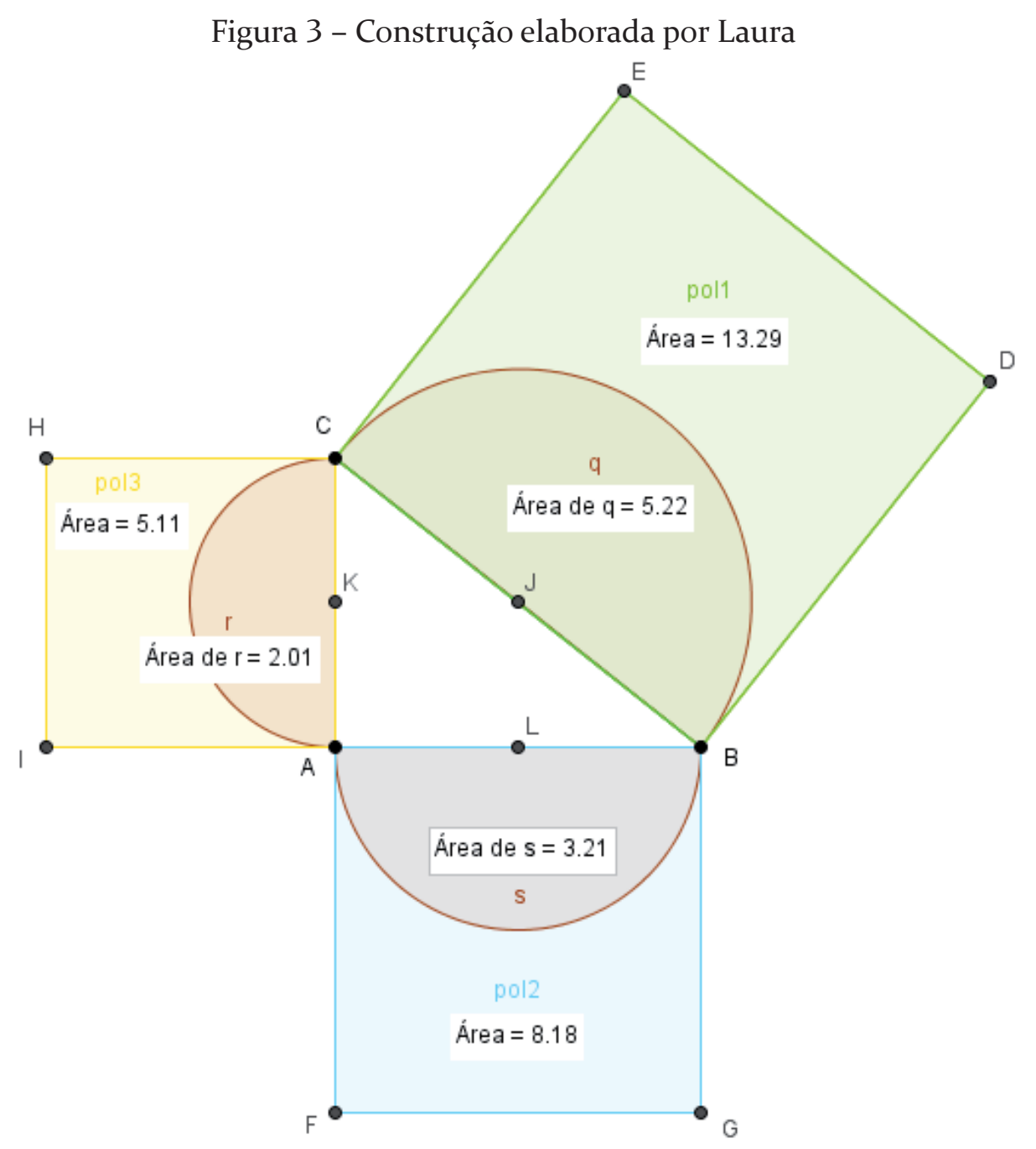

Fonte: dados da pesquisa de doutorado da segunda autora 
Embora não com a mesma velocidade de inserções de uma sala de bate-papo, observamos nessas discussões no fórum conversas entrecruzadas (Borba, 2004) que mudaram a natureza da produção de conhecimento acerca das funcionalidades do GeoGebra, o que pode ser observado no modo como os professores relacionaram os conteúdos matemáticos com abordagens distintas das que propusemos, ao explorarem o software pensando na produção de conhecimento matemático de seus alunos. A professora Carina explorou outras possibilidades para a construção do triângulo, por julgar mais significativo para seus alunos que entendessem que o Teorema de Pitágoras só se aplica a triângulos retângulos. A professora Camila criou uma planilha para que os alunos tivessem mais uma opção para facilitar ainda mais a visualização da variação das medidas das figuras. A professora Laura explorou a funcionalidade de criar círculos no GeoGebra e articulou a abordagem que propusemos com a abordagem proposta na situação de aprendizagem do material didático do estado de São Paulo (São Paulo, 2014). E ainda acrescentou um terceiro objetivo, envolvendo área de semicírculos.

Ou seja, os professores, pensando em suas salas de aula, apresentaram suas ideias para adaptações, as quais provavelmente já tinham emergido ao longo da semana, antes do encontro síncrono. Contudo, em meio às conversas com as proponentes do curso e com colegas, os professores repensaram suas ideias, buscando aprimorar ainda mais suas adaptações.

Julgamos que seria válido apresentar essa última situação, em que relatamos as adaptações da professora Laura, pois, embora não tenha gerado discussões, essa professora demorou para se manifestar no encontro síncrono, e, independentemente de ela ter sido influenciada por alguma conversa no fórum, ou não, ela trouxe um elemento novo para o curso, pelo qual já almejávamos desde a etapa de planejamento. Esse elemento foi a articulação da atividade no software com o material didático utilizado nas escolas estaduais paulistas.

Além disso, observamos aqui que o fórum de discussões, dentro do AVA, apresentou algumas características do rizoma (Deleuze \& Guattari, 1995). Ou seja, embora tenhamos buscado provocar certas discussões a partir da abordagem que propusemos para essa atividade, não foi nossa frase inicial que originou as adaptações e/ou o compartilhamento de ideias. Ou seja, o rumo tomado não se expandiu de forma ramificada a partir de uma única abordagem sugerida, ele era alterado a cada postagem. Primeiramente a professora Carina mencionou uma adaptação em que não ficou claro para nós o propósito da inclusão de mais um triângulo. Ao mesmo tempo, outros professores estavam colocando suas considerações e nós também estávamos buscando uma forma de ajudar a professora Camila a automatizar a sua planilha. Automatização essa que chamou a atenção de Carina. Ainda, paralelamente, Laura sugeriu adaptações que perpassaram o objetivo que propusemos inicialmente com essa atividade. 
Além disso, muitas outras ações que os professores poderiam desenvolver paralelamente ao encontro síncrono passaram despercebidas por nós, mas, mesmo assim, fizeram parte dos diferentes rumos tomados nesse Multiálogo, do qual escolhemos um pequeno recorte para discutir aqui.

\section{Considerações finais}

Neste artigo tivemos o propósito de apresentar e discutir recortes dos dados provenientes de um curso de formação continuada para professores de Matemática, que ocorreu na Diretoria de Ensino de Bauru/SP e fez parte de uma das ações que vêm sendo realizadas pelo projeto "Mapeamento do uso das tecnologias da informação nas aulas de Matemática no Estado de São Paulo”, vinculado ao OBEDUC.

Assim, esclarecemos os objetivos desse projeto e trouxemos resultados de pesquisas vinculadas a ele que apontam problemas com infraestrutura e também com a formação de professores como um dos percalços para a integração das tecnologias nas aulas de Matemática do Ensino Fundamental de escolas públicas paulistas. Diante disso, posicionamos o curso como uma das ações que realizamos, cujo intuito foi o de atender às necessidades dos professores, de forma a provocar reflexões sobre a integração das tecnologias digitais dentro do contexto escolar de cada um dos participantes. Revelamos como se desenvolveu o curso ao longo de suas quarenta horas. Em seguida, apresentamos a noção de Multiálogo (Borba, 2004) e de Rizoma (Deleuze \& Guattari, 1995), que são aportes teóricos que nos auxiliam a analisar os dados aqui apresentados e discutidos, produzidos no fórum de discussões do AVA Moodle, utilizado nos momentos virtuais do curso. Um movimento de ações trouxe à tona as ideias dos professores cursistas, ao adaptar atividades propostas, levando em consideração seus ambientes educacionais.

Concluímos que a discussão dos professores no fórum, mesmo não sendo no bate-papo, apresentou características de multiálogo (Borba, 2004), em particular, no que se refere às conversas entrecruzadas. Ou seja, dentro de nosso contexto, evidenciamos que tais conversas modificaram a natureza da produção de conhecimento acerca das funcionalidades do GeoGebra, o que foi observado no modo como os professores entrelaçaram os conteúdos matemáticos com abordagens distintas das que havíamos proposto, pois exploraram o software, tendo em mente a produção de conhecimento matemático de seus alunos. Além disso, evidenciamos algumas características de rizoma (Deleuze \& Guattari, 1995) nessas discussões, que não seguiram uma sequência predefinida, ou seja, aconteceram de modo que as ações provocadas geraram inquietações por parte tanto das proponentes quanto dos professores e resultaram em adaptações na atividade, incluindo o próprio objetivo. 
Por fim, não esgotamos essa discussão e reiteramos aqui algumas reflexões emergentes no decorrer da escrita desse artigo: Seriam as características de Multiálogo e Rizoma, aqui evidenciadas, frutos da forma de comunicação que ocorreu nesse caso em particular? Seriam frutos da forma de comunicação presencial que já havia sido estabelecida anteriormente? Seriam frutos da relação dialética que cada professor assumiu com o software GeoGebra?

Para a primeira questão, a nossa resposta seria sim, já que, pelo fato de essas atividades terem sido disponibilizadas anteriormente à etapa presencial, os professores tiveram um tempo maior para analisar e refletir acerca das várias possibilidades de adaptações, anexando-as posteriormente no fórum e compartilhando, assim, com os demais professores. Em função da programação do curso, presencialmente não tínhamos tempo hábil para o compartilhamento das atividades adaptadas, nos limitávamos apenas a discutir possibilidades de adaptações, e virtualmente isso foi colocado em prática.

Para a terceira questão, a resposta também é sim, pois, desde o início do curso, os professores demonstraram um forte interesse em se aprofundar no GeoGebra, e de fato cumprimos esse objetivo ao longo do curso.

Para a segunda questão ainda não temos uma resposta definitiva, pois alguns professores que não se manifestavam muito presencialmente participavam ativamente das discussões no fórum, e a comunicação estabelecida nesse ambiente perpassou os grupos que já haviam sido estabelecidos presencialmente. No entanto, não temos elementos que nos permitam afirmar que isso teria acontecido, caso eles não tivessem tido um contato presencial prévio. Ou seja, alguns professores que não se comunicavam com frequência uns com os outros presencialmente acabaram interagindo mais entre si no fórum.

Ainda estamos refletindo acerca dessas questões, e outras estão emergindo. Assim, elas estão ampliando nosso campo de estudo e dando indícios de respostas que têm nos movido nos encaminhamentos de futuras ações dentro do projeto, as quais envolvem, principalmente, a articulação entre as pesquisas em Educação Matemática e os professores atuantes na Educação Básica do estado de São Paulo. Finalmente, o desenvolvimento de projetos dessa natureza, fomentados pelo OBEDUC, possibilita uma maior aproximação entre a Universidade e Escola, já que proporciona o envolvimento de professores pesquisadores, que orientam projetos de pesquisa de alunos da graduação, de mestrado e doutorado do programa de pós-graduação; e de professores de Matemática da Educação Básica, criando assim um grupo que desenvolve um trabalho colaborativo de pesquisa. 


\section{Referências}

Andrade, P. F., \& Baldoni, A. C. (2014). A escola pública e o uso do computador: um olhar para a estrutura física dos laboratórios de informática das escolas de Bauru/SP. Anais 2 Fórum do GT6 da Sociedade Brasileira de Educação Matemática (SBEM) (p.1-1). Rio de Janeiro: Sociedade Brasileira de Educação Matemática (SBEM).

Andrade, P. F., Baldoni, A. C. P., \& Javaroni, S. L. (2014). A escola pública e o uso do computador: um olhar para a estrutura física dos laboratórios de informática das escolas da Diretoria de Ensino de Bauru. In Anais 26 Congresso de Iniciação Científica (pp.1-1). Bauru: Universidade Estadual Paulista "Júlio de Mesquita Filho".

Borba, M. C. (2004). Educação matemática: pesquisa em movimento. São Paulo: Cortez.

Borges, L. (2014). A utilização dos laboratórios de informática nas escolas estaduais de Rio Claro e região. In Anais 26 Congresso de Iniciação Científica (pp.1-1). Rio Claro: Universidade Estadual Paulista "Júlio de Mesquita Filho".

Chinellato, T. G. (2014). O uso do computador em escolas públicas estaduais da cidade de Limeira/SP. Dissertação de Mestrado em Educação Matemática, Instituto de Geociências e Ciências Exatas, Universidade Estadual Paulista - UNESP, Rio Claro, SP.

Chinellato, T. G., \& Javaroni, S. L. (2013). A formação continuada do professor de matemática no Estado de São Paulo. In Actas del 7 Congreso Iberoamericano de Educación Matemática (CIBEM) (pp. 6656-6663). Montevideo: Sociedade de Educação Matemática Uruguaya.

Chinellato, T. G., \& Javaroni, S. L. (2014). A formação dos professores de Matemática para o uso de tecnologias digitais na cidade de Limeira/SP. In Anais 2 Congresso Nacional de Formação de Professores e XII Congresso Estadual Paulista sobre Formação de Educadores - Por uma revolução no Campo da Formação de Professores. (pp. 3335-33345). Águas de Lindóia: Pró-Reitoria de Graduação da UNESP.

Deleuze, G., \& Guattari, F. (1995). Mil platôs - capitalismo e esquizofrenia. Rio de Janeiro: Editora 34.

Ferreira, M. J. A., Zampieri, M. T., \& Queiroz, S. M. (2013). Ambientes virtuais e suas potencialidades para o ensino de aprendizagem de matemática: comunicação e colaboração. In Anais 7 Congreso Iberoamericano de Educación Matemática (pp. 6688-6697). Montevideo, Uruguay: Sociedade de Educação Matemática Uruguaya.

Firme, I. C., \& Paulo, R. M. (2014). O uso de tecnologias na aula de Matemática: uma visão a partir da análise das condições do Programa Acessa Escola. In Anais 2 Fórum do GT6 da Sociedade Brasileira de Educação Matemática (SBEM) (p.1-1). Rio de Janeiro: Sociedade Brasileira de Educação Matemática (SBEM).

Freire, P. (2005). Pedagogia do oprimido (49a reimp.). Rio de Janeiro: Paz e Terra.

Freitas, P. P. (2014). Perspectivas teóricas sobre as características dos professores que utilizam as tecnologias informáticas em suas aulas de Matemática. In Anais Encontro Brasileiro de Estudantes de Pós-Graduação em Educação Matemática (Ebrapem) (pp. 1-1). Recife: Universidade Federal de Pernambuco (UFPE).

Medeiros, D. O. (2014). Mapeamento do uso dos computadores do Programa Acessa Escola nas aulas de matemática das escolas públicas de Presidente Prudente. In Anais 26 Congresso 
de Iniciação Científica (pp. 1-1). Presidente Prudente. Universidade Estadual Paulista "Júlio de Mesquita Filho".

Oliveira, F. T. (2014). A inviabilidade do uso das tecnologias da informação e comunicação no contexto escolar: o que contam os professores de Matemática? Dissertação de Mestrado em Educação Matemática, Instituto de Geociências e Ciências Exatas, Universidade Estadual Paulista - UNESP, Rio Claro, SP.

São Paulo (Estado). (2014). Material de apoio ao currículo do estado de São Paulo. Caderno do professor. Matemática. (vol. 2, 8a série/9o ano). São Paulo, SP.

Silva, A., Zampieri, M. T., Javaroni, S. L., \& Chinellato, T. G. (2014). A inserção dos computadores nas aulas de matemática: perspectivas a partir de um estudo na cidade de Rio Claro. In 2 Congresso Nacional de Formação de Professores e 12 Congresso Estadual Paulista sobre Formação de Educadores - Por uma revolução no campo da formação de professores (pp. 3405-3414). Águas de Lindóia: Pró-Reitoria de Graduação da UNESP.

Submetido em: 25/01/2016

Aceito em: 05/03/2016 
